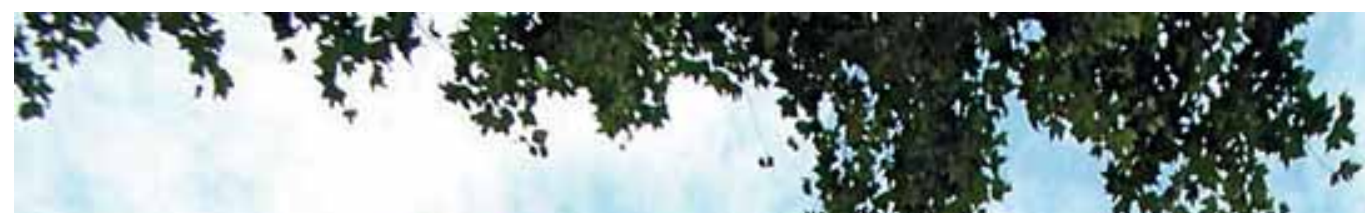

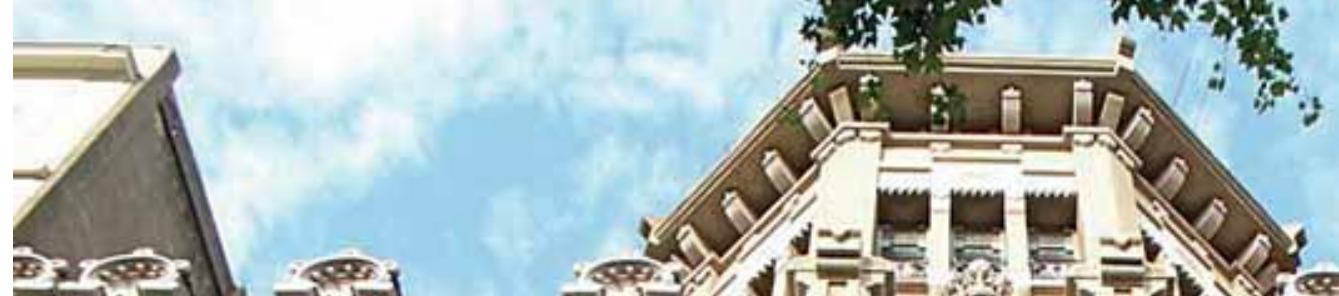

tean

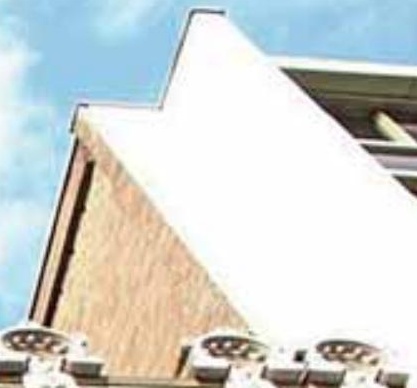

.

ะัตือ

10

(6.8.6.6.0)

$7 \operatorname{senth}-1$ $\because n=0$

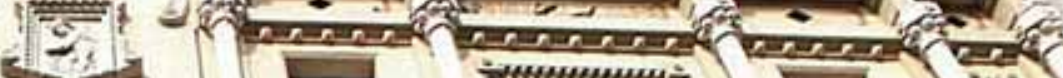
-1 . El $\therefore$ TH:

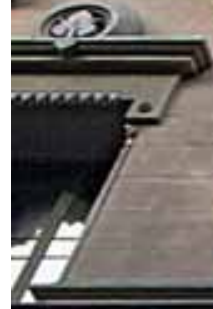

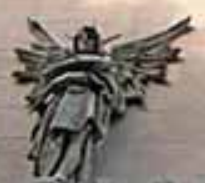

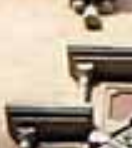

$x=$

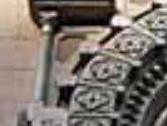

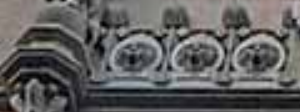

erase

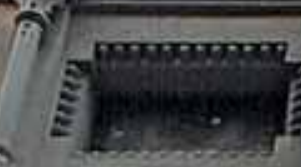

\$.

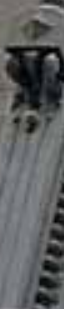

3. 1.0.

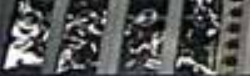

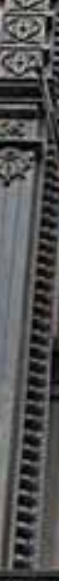

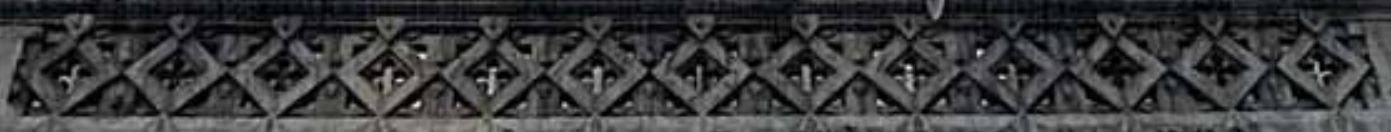
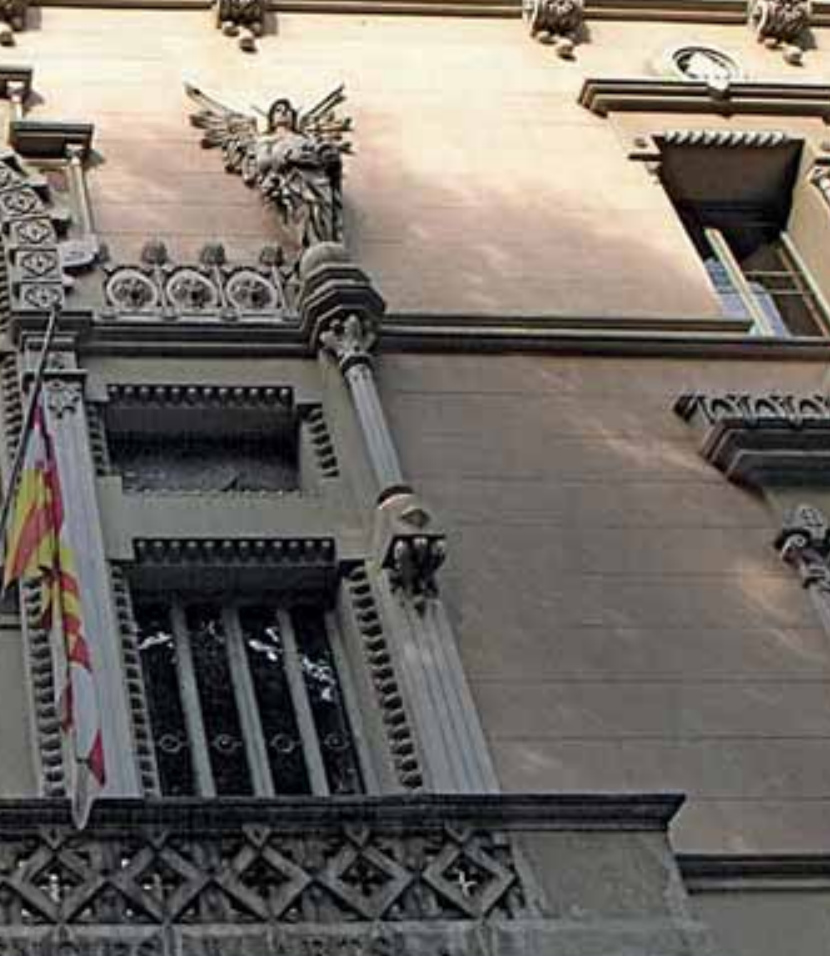

Qrasasa:
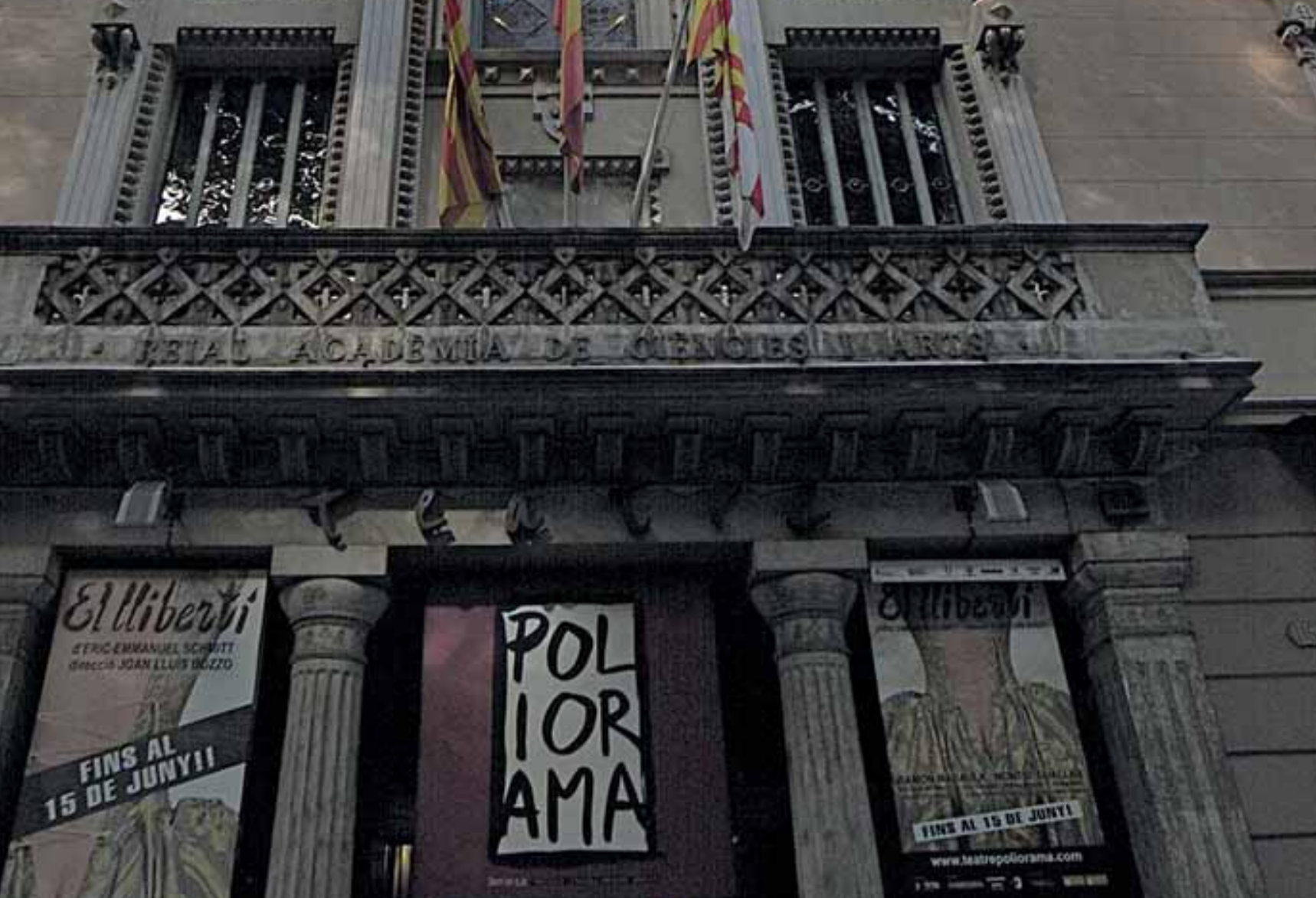


\section{ANTONI DE MARTÍ I FRANQUĖS I LA GENERACIÓ ESPONTÀNIA ELS CONFLICTES ENTRE CIÈNCIA I RELIGIÓ EN EL TREBALL DEL NATURALISTA}

\section{Agustí CAMÓs}

Antoni de Martí i Franquès, el naturalista tarragoní que va viure en la segona part del segle xvIII i primers decennis del XIX, conegut especialment pels seus notables experiments dedicats a l'estudi de la composició de l'aire atmosfèric, dedicà bona part del seu treball experimental a estudiar la generació espontània. A través dels manuscrits de Martí i Franquès que es conserven i pel testimoni dels seus contemporanis, sabem que estava convençut d'haver comprovat experimentalment l'existència d'aquest fenomen. Però, com que era un fervent catòlic, no va voler publicar res sobre aquest tema en vida per temor de ser acusat d'heretge. Tampoc el seus descendents van publicar res de la seva obra per prejudicis religiosos.

Paraules clau: Antoni de Martí i Franquès, generació espontània, segle XVIII i XIX, Catalunya, religió.

No és el primer cop que en aquesta revista es parla d'Antoni de Martí i Franquès, «El nostre heroi», tal com el qualifica Josep Grau-Bové en el títol de l'article publicat en el número 72 de MÈTODE. I no és estrany, ja que Martí ha estat un dels científics catalans més destacats, però paradoxalment coneixem molt poc de la seva activitat. Grau-Bové abordava en l'article esmentat els treballs que tingueren una major repercussió fins i tot fora de les nostres fronteres: les seves investigacions sobre la composició de l'aire. En aquest article tractarem sobre un altre dels temes que més el van preocupar i sobre els quals va dur a terme més investigacions, la generació espontània. Malauradament Martí no va publicar mai res sobre aquest tema per raons que tractarem d'aclarir.

\section{LA GENERACIÓ ESPONTÀNIA}

El Diccionari de la llengua catalana de l'Institut d'Estudis Catalans defineix la generació espontània com «generació segons la qual la matèria morta generaria éssers vivents». Aquesta concepció, que planteja que la matèria inorgànica o les restes d'organismes podri- en generar per si mateixes nous éssers vius, ha estat el centre d'un llarg debat científic que d'alguna manera es prolonga fins als nostres dies. Molts filòsofs de la Grècia clàssica afirmaren l'existència de la generació

\author{
«MARTÍ I FRANQUÈS TRACTAVA DE \\ RESOLDRE UNA SĖRIE DE CONFLICTES \\ ORIGINATS PERQUĖ ELS RESULTATS DE LA \\ SEVA RECERCA CIENTÍFICA LI SEMBLAVA \\ QUE ENTRAVEN EN CONTRADICCIÓ \\ AMB LES SEVES FERMES CREENCES \\ RELIGIOSES»
}

espontània, però va ser la defensa que en va fer Aristòtil la que va tenir major impacte en la cultura occidental a causa de l'enorme influència d'aquest gran pensador. A partir del segle XVII es desenvolupà un important debat en la comunitat científica entre aquells que la de-

Les idees de Martí i Franquès sobre la generació espontània van continuar presents en la Reial Acadèmia de Ciències i Arts de Barcelona després de la seua mort. Els seus plantejaments es reflecteixen en diferents memòries i en el si de la institució es va debatre la possibilitat de publicar els treballs del naturalista, però mai no es va arribar a portar a terme. En la imatge, la façana de la Reial Acadèmia de Ciències i Arts en l'actualitat. 
fensaven i els que la negaven. Grans científics com Redi, Harvey o Spallanzani negaren que existís, mentre que en els mateixos segles altres científics importants com Buffon, Needham, Lamarck o el mateix Martí la defensaren (Farley, 1977). Probablement el debat més conegut sobre aquest tema és el que enfrontà Pouchet i Pasteur en la segona part del segle XIX, que culminà amb el reconeixement majoritari dels famosos experiments a través dels quals Pasteur tractava de demostrar la inexistència de la generació espontània. No obstant això, tampoc aquest debat tancà la polèmica, ja que entre molts evolucionistes del segle XIX es continuà defensant el procés, ja que feia més fàcil explicar la formació dels primers éssers vius a partir de la matèria inorgànica. Entre els defensors de la generació espontània en aquesta època es trobava el mateix Darwin, que, si bé no defensà mai el procés de manera pública, coneixem que privadament sí que ho va fer (Peretó, 2009).

En la segona part del segle Xx la generació espontània ha estat molt malament considerada, en bona part a causa del gran prestigi de què gaudia Pasteur i els seus brillants experiments. De fet, el menyspreu amb què s'ha tractat aquest procés encara es reflecteix en molts llibres de text de començament del segle XXI, amb frases com «La concepció espontaneista s'ha mantingut per ser una explicació immediata i senzilla que dóna resposta a fets o problemes quotidians sense contrastar experimentalment» (Rubio Sáez et al., 2008: 32). La història de la ciència ens permet conèixer que durant segles grans científics favorables i contraris a la generació espontània, com el mateix Martí, van fer nombrosos experiments per tal de defensar les seves posicions: així doncs, seria molt més profitós per als alumnes reflexionar sobre les raons que van portar aquests científics a prendre's tan seriosament aquesta qüestió, que no liquidar-la amb afirmacions menyspreatives.

\section{L'ACTIVITAT CIENTÍFICA DE MARTÍ I FRANQUÈS}

Gràcies al gran treball del pioner de la història de la ciència a Catalunya Antoni Quintana Marí coneixem força dades de la biografia de Martí i Franquès. Es tracta d'un personatge benestant que va nàixer el 1750 i morí el 1832, vivint entre Altafulla, la seva població natal, Tarragona, on establí la seva residencia a partir de l'any 1798 , i Barcelona, on viatjà amb certa freqüència i participà en les seves institucions científiques. Cal destacar també que entre 1801 i 1802 va fer un llarg viatge per les principals ciutats europees com París, Londres i Brusselles, on visità diferents institucions acadèmiques.

En relació a la seva activitat científica cal destacar que de jove gairebé no va rebre ensenyament en aquest camp, però que va adquirir una extraordinària formació
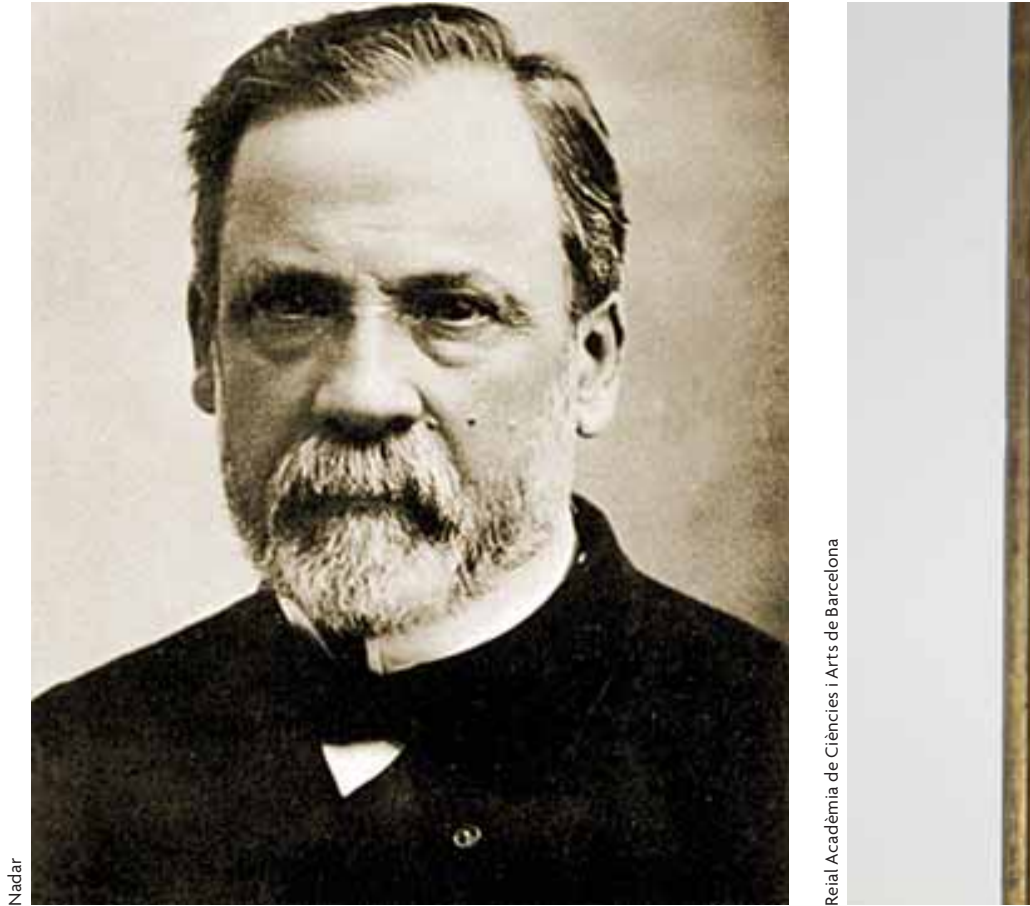

Probablement el debat més conegut sobre la generació espontània és el que enfrontà Pouchet i Pasteur en la segona part del segle XIX, que culminà amb el reconeixement majoritari dels famosos experiments a través dels quals Pasteur tractava de demostrar la inexistència de la generació espontània. En la segona part del segle xx la generació espontània ha estat molt mal considerada, en bona part a causa del gran prestigi de què gaudia Pasteur i els seus brillants experiments. En la imatge, Louis Pasteur, retratat pel fotògraf Nadar.

de forma autodidacta a través de la gran biblioteca que va anar formant al llarg dels anys i que li va permetre conèixer l'activitat científica que es desenvolupava a Europa. Va ser membre de la Reial Acadèmia de Ciències i Arts i la Reial Acadèmia Mèdico-Pràctica de Barcelona, on presentà cinc memòries de les quals en coneixem tres. D'entre aquestes destaca la que portava per títol Sobre la cantidad de aire vital que se halla en el aire atmosférico, on establí els percentatges d'oxigen i nitrogen que conté l'aire així com la seva constància, i que tingué un considerable ressò internacional (Grau-Bové, 2012). A més, establí alguns contactes amb científics estrangers com Francesc Aragó i Jean-Baptiste Biot, especialment quan collaborà amb els expedicionaris francesos en els treballs per mesurar la longitud del meridià terrestre.

La major part de la seva activitat científica la desenvolupà en els gabinets que va establir primer a Altafulla i més tard a Tarragona. En ells va fer nombrosos experiments sobre l'aire atmosfèric, la nutrició i la reproducció dels vegetals i la generació espontània. La documentació més important que s'ha conservat sobre la seva tasca experimental consisteix en 3.000 pàgines manuscrites de difícil lectura, que es calcula que recullen unes 


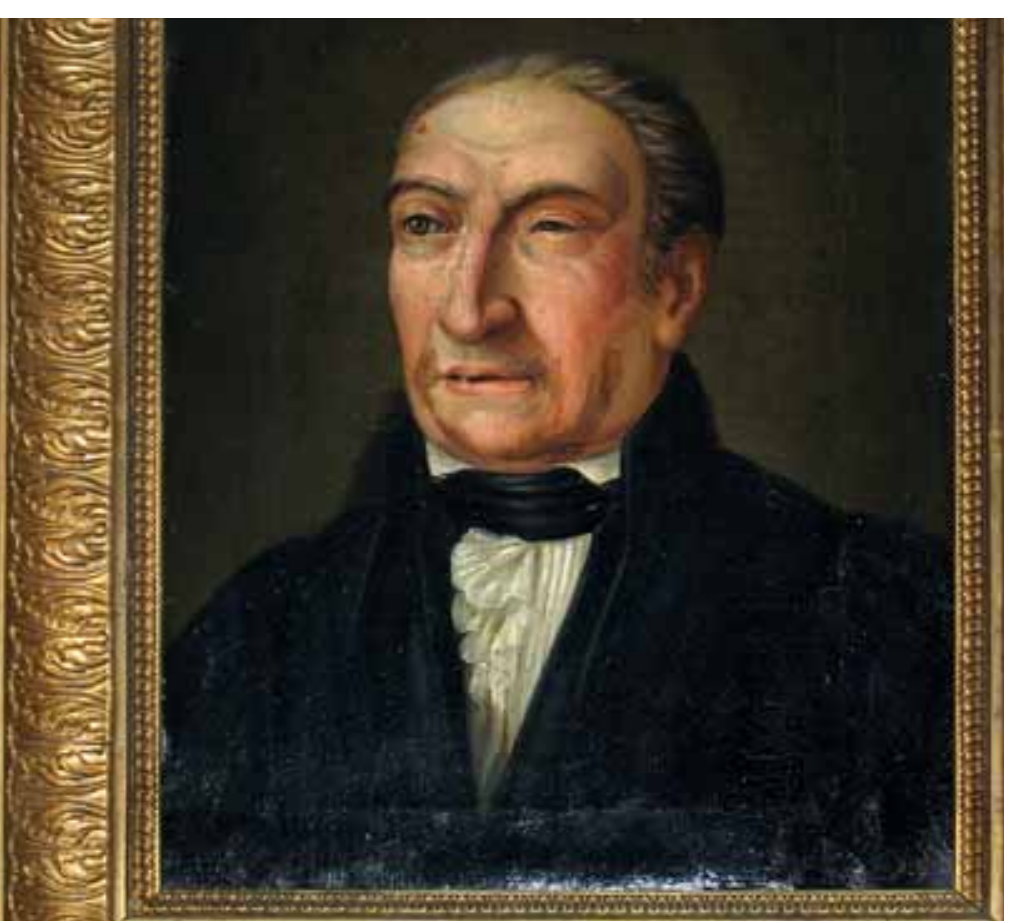

Martí i Franquès gairebé no va rebre ensenyament en el camp científic, però va adquirir una extraordinària formació de forma autodidacta a través de la gran biblioteca que va anar formant al llarg dels anys i que li va permetre conèixer l'activitat científica que es desenvolupava a Europa.Retrat a l'oli d'Antoni Martí realitzat per Josep Arrau, que es conserva a la Reial Acadèmia de Ciències i Arts de Barcelona.

\section{«FINS I TOT DESPRÉS DE L'ENTREVISTA AMB L'ECLESIÀSTIC QUE LI ASSEGURÀ QUE ELS SEUS PLANTEJAMENTS CIENTÍFICS NO EREN CONTRARIS A LA RELIGIÓ, MARTÍ CONTINUÀ NEGANT-SE A PUBLICAR CAP DELS SEUS RESULTATS»}

50.000 observacions i que únicament s'han transcrit en una petita part. Aquestes pàgines sols recullen el treball experimental que va desenvolupar quan tenia entre 66 i 78 anys. De l'enorme treball que havia realitzat abans d'aquesta edat tan sols coneixem el que apareix en les tres memòries que es conserven i el testimoni dels seus contemporanis, ja que la documentació que havia generat es va perdre en l'assalt de les tropes de Napoleó a Tarragona.

\section{ELS EXPERIMENTS DE MARTÍ I FRANQUÈS SOBRE LA GENERACIÓ ESPONTÀNIA}

Tenim constància de l'intens treball experimental que Martí va fer sobre la generació espontània a través de tres conjunts de dades: el testimoni dels seus contemporanis, els seus manuscrits i la singular conversa que mantingué amb un clergue (Camós, 2013b). El metge Jaume Parcet, un amic de Martí que el visità en nombroses ocasions al seu gabinet de Tarragona, va escriure a la necrologia que li dedicà poc després de la seva mort:

Se le ha oído repetidas veces que a un cadáver lo reduciría todo a una masa térrea, y que ésta la dispondría después de un modo que todos sus principios, o la mayor parte de ellos, constituirían organizaciones vegetales improcedentes también de símil; y pertenecientes estas y las anteriores a la última clase de Ligneo [sic]. (Parcet, 1907).

Igualment, Josep Arrau, un jove pintor que va ser membre de la Real Academia de Ciencias y Artes de Barcelona, i que participà en una tertúlia a Barcelona on també hi assistia Martí quan ja era un ancià, explicava que el científic altafullenc estava segur d'haver produiit plantes per generació espontània. Aquest testimoni s'inclou a la biografia que va escriure Elías de Molins:

Entre estas discusiones se logró varias veces que el señor Martí explanase los medios que se valía para lograr artificialmente la formación y crecimiento de las plantas acuáticas criptógamas que el denominaba trémulas y más corrientemente materia verde, y la teoría que en su concepto podía admitirse para explicar ese maravilloso fenómeno. (Elías de Molins, 1895).

Un altre testimoni és el de Fèlix Torres Amat, un notable clergue igualment amic de Martí. En la biografia de Martí que inclogué en la seva obra Memorias para ayudar a formar un diccionario crítico de los escritores catalanes escrivia:

Estos ensayos tuvieron por objeto la producción artificial de los vegetales por la organización de la materia inorgánica; habiendo alcanzado a formar a su arbitrio varias conservas, tremolas y otras plantas celulares, teniéndose presentido haberse extendido igualmente a algunas vasculares. (Torres Amat, 1836).

El mateix Martí, en un dels manuscrits que es conserven i que Quintana va transcriure en la seva obra sobre el científic, registrava dades sobre els experiments que realitzava sobre la generació espontània:

Un vaso con un excremento de palomo, y poca agua no dio gas ni mata. [materia] verde en Dbre. [diciembre] hasta el cabo de 11 días; y un frasquito tapado de medida lleno de la agua del vaso en que estuvo el excto. [excremento] por espacio de 24 horas dio gas y mata. verde al cabo de 5 días. Dbre. 23 y 27 exp. [experimento] 3 y 7. (Quintana, 1935).

És a dir, estava convençut de produir experimentalment organismes vius, materia verde, a partir de restes d'organismes, però arribà a preguntar-se si era possible produir el mateix procés a partir de solament matèria 
inorgànica. En un altre apartat del mateix manuscrit podem trobar la següent reflexió també transcrita per Quintana:

Así como el gas carbo. [carbónico] se descompone por la mata. [materia] verde, apropiándose esta su carbón con que se alimenta, y crece, y soltando oxígeno en gas, dicho gas carbónico con la agua pura y sin intermedio alguno, formaría mat. verde? (Quintana, 1935).

Un altre notable testimoni prové d'una aclaridora entrevista que Martí mantingué l'any 1819 a Barcelona amb un eclesiàstic amic seu. En l'entrevista Martí tractava de resoldre una sèrie de conflictes originats perquè els resultats de la seva recerca científica li semblava que entraven en contradicció amb les seves fermes creences religioses. Els neguits de Martí se centraven en tres qüestions: la antiguitat de la Terra, la transformació dels organismes i la generació espontània (Camós, 2013b). Pel que fa a aquesta darrera qüestió, Martí explicà a l'eclesiàstic que era capaç de produir experimentalment la generació espontània. Torres Amat, molt probablement l'eclesiàstic amb qui Martí s'entrevistà, recollí la conversa a la biografia que li dedicà en el seu diccionari:

Enseguida explicó el Sr. Martí a su amigo la producción artificial que él había logrado hacer dentro de botellas de agua de muchas plantas confesvas [sic], algunas de las cuales tenían ya 20, o 30 años, y presentándose con un microscopio otra partes más pequeñas. (Torres Amat, 1836).

Cal ressaltar que, de manera una mica sorprenent si considerem com era bona part del clergat espanyol de l'època, Martí va rebre com a resposta que les tres qüestions que plantejà eren compatibles amb la religió catòlica.

\section{LES RAONS DE MARTÍ I DELS SEUS DESCENDENTS PER NO PUBLICAR RES SOBRE LA SEVA RECERCA}

Com hem dit, Martí tan sols va fer públiques cinc memòries entre 1787 i 1792, quan tenia al voltant de quaranta anys. Posteriorment no va fer públic cap resultat de la seva recerca científica, tot i que tenim constància que va continuar el seu enorme treball experimental fins quan tenia prop de vuitanta anys. Només es va imprimir una de les seves memòries, que portava per títol Experimentos y observaciones sobre los sexos y fecundación de las plantas, on rebatia les tesis sobre la reproducció dels vegetals del científic i clergue catòlic italià Lazzaro Spallanzani, qui, per altra banda, era radicalment contrari a la generació espontània.

Les raons que podrien explicar el fet que es negués a publicar els seus treballs serien per una banda la seva inseguretat i timidesa, però sobretot la por a entrar en contradicció amb les seves fermes creences catòliques i ser acusat d'heretge. Aquesta idea la reflecteix de forma

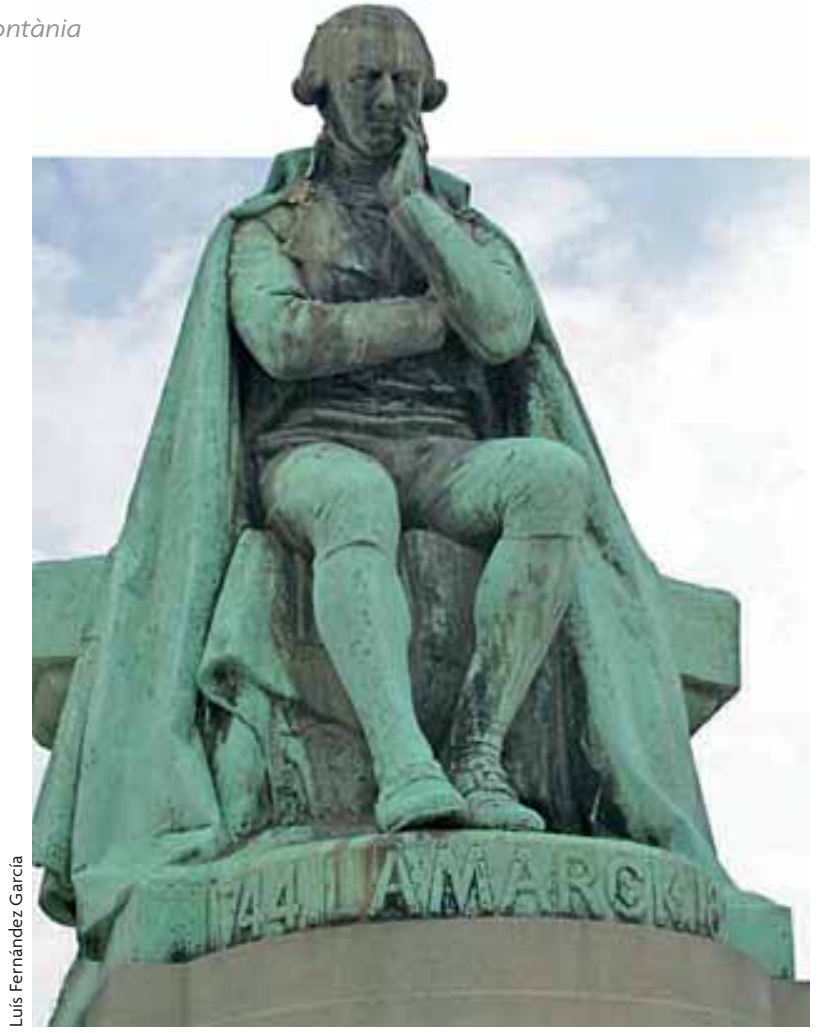

Martí i Franquès estava convençut de ser capaç de controlar experimentalment la generació espontània i produir a voluntat petites algues unicel-lulars. A més, aquestes petites algues amb el pas del temps s'anaven convertint en plantes cada cop més complexes, en un procés de transformisme vegetal proper als plantejaments que defensava a França el seu contemporani Jean-Baptiste Lamarck. En la imatge, una estàtua dedicada a Lamarck al Jardin des Plantes de París.

\section{"MARTÍ DEFENSAVA L'EXISTĖNCIA DE LA GENERACIÓ ESPONTÀNIA I ESTAVA CONVENÇUT DE SER CAPAÇ DE CONTROLAR EXPERIMENTALMENT AQUEST PROCÉS I PRODUIR A VOLUNTAT PETITES ALGUES UNICEL.LULARS"}

contundent el seu amic Torres Amat a la seva biografia: «[...] fué el temor de que muchos, más por ignorancia que por malicia, se levantarían contra él. Y quizás le acusarían de hereje o impío.»

Fins i tot després de l'esmentada entrevista amb l'eclesiàstic que li assegurà que els seus plantejaments científics no eren contraris a la religió, Martí continuà negant-se a publicar cap dels seus resultats. Alguns dels seus contemporanis coneixedors de la seva valuosa tasca científica, com el mateix Torres Amat, insistiren infructuosament a Martí perquè publiqués els seus resultats, però Martí es negà a fer-ho fins a la seva mort. Entre aquests contemporanis destaca el que podem considerar un dels seus deixebles, el naturalista Agustí Yáñez, que 
en l'edició de 1820 del seu llibre Lecciones de historia natural escrivia:

Este sabio laborioso é infatigable se está ocupando en esperiencias [sic] muy delicadas relativas à las plantas criptógamas; las cuales, si llegan a publicarse, no dudo que causarán mutaciones de mucha consideración en la fisiología de los vegetales. (Yáñez, 1820).

Després de la mort de Martí els mitjans científics barcelonins continuaren sent conscients de la importància de la tasca científica de l'altafullenc, i també es mogueren entre la voluntat de publicar els resultats de la seva recerca científica i la por a la resposta de l'església catòlica. Així succeí de manera reiterada a la Real Academia de Ciencias y Artes de Barcelona, on les idees de Martí sobre la generació espontània continuaren presents i es reflectiren en diferents memòries, $\mathrm{i}$ on en diverses ocasions es va debatre la possibilitat de publicar els treballs de Martí, però mai es va arribar a dur a terme (Camós, 2013b).

Qui seguia tement pels treballs de Martí era la seva família, que poc després de la seva mort va fer analitzar els seus manuscrits per religiosos i doctes naturalistes, com explica Elías de Molins (1895). Més d'un segle després, segons el testimoni d'un descendent de Martí, el prestigiós naturalista Joaquim Castellarnau, la seva biblioteca fou de nou expurgada probablement per motius religiosos. Quintana recull el següent testimoni de Castellarnau:

Antoni de Martí, com molts savis del seu temps, era partidari de la "Generació espontània" doctrina aquesta com és ben sabut, condemnada i combatuda per l'Ortodòxia amb el mateix aferrissament que més tard ho fou el darwinisme. ¿Pogué això influir en l'anima excessivament religiosa, d'un dels descendents i hereu universal -com aleshores era costumperquè aquesta munió de llibres venerables no fossin conservats amb l'alta estima que mereixen? (Quintana, 1935).

Havia passat més d'un segle, però de nou la generació espontània tornava estar en el centre del problema.

\section{CONCLUSIÓ}

Encara que Martí i Franquès no publiqués res sobre la generació espontània en bona part a causa de la por de ser acusat d'heretge, a través del testimoni dels seus contemporanis i d'algun dels seus manuscrits tenim constància que no tan sols defensava la seva existència, sinó que estava convençut de ser capaç de controlar experimentalment aquest procés i produir a voluntat petites algues unicel·lulars. A més, aquestes petites algues amb el pas del temps s'anaven convertint en plantes cada cop més complexes, en un procés de transformisme vegetal proper als plantejaments que defensava a França el seu contemporani Jean-Baptiste Lamarck (Camós, 2013 ).
El dia que es faci una transcripció completa de les 3.000 pàgines manuscrites que s'han conservat del seu treball experimental dels darrers anys d'activitat científica, podrem comprendre millor l'abast de la seva tasca experimental i les seves idees sobre la generació espontània i el transformisme.

REFERÈNCIES

CAMós, A., 2013a. «Antoni de Martí i Franquès, la generación espontánea y la transformación de los organismos». Asclepio, 65(2). DOI: <10.3989/ asclepio.2013.22>.

CAMós, A., 2013b. «Antoni de Martí i Franquès i Fèlix Torres Amat: ciència i dissidència religiosa a la Catalunya d'inici del segle XIX». Actes d'Història de la Ciència i de la Tècnica, nova època/vol 6 (1), 1-32. DOI 10.2436/20.2006.01.171 Disponible en: <http://revistes.iec.cat/index.php/AHCT/article/view/65925>.

Elías DE Molins, A., 1895. Diccionario biográfico y bibliográfico de escritores y artistas catalanes del siglo XIX. Impremta de Calzada. Barcelona.

FARLEY, J., 1977. The Spontaneous Generation Controversy from Descartes to Oparin. Johns Hopkins University Press. Baltimore.

Grau-Bové, J., 2012. «El nostre heroi Martí i Franquès». Mètode, 72: 14-19. Disponible en: <http://metode.cat/Revistes/Article/El-nostre-heroi-Marti-iFranques>.

PARCET, J., 1907. «Necrología de Dn. Antonio Martí y Franqués escrita por el doctor Jaime Parcet, leída el 20 noviembre 1832». Boletín Arqueológico de Tarragona, 20(1): 695-700.

Peretó, J., 2009. «A partir d'un inici tan simple. L'origen de la vida: Un problema de química amb història». Treballs de la Societat Catalana de Biologia, 60: 31-44. DOI: <10.2436/20.1501.02.75>.

QuintanA, A., 1935. «Antoni Martí i Franquès. Memòries originals. Estudi biogràfic i documental». Memòries de l'Acadèmia de Ciències i Arts de Barcelona, 3(XXIV).

Rubio Sáez, N.; Pulido Bordallo, C i J. M. Roiz García, 2008. Ciències per al món contemporani. Barcanova. Barcelona.

TORRes AMAT, F., 1836. Memorias para ayudar a formar un diccionario crítico de los escritores catalanes. Impremta d'A. Verdaguer. Barcelona.

YAÑEZ, A., 1820. Lecciones de historia natural. Oficina de la Vídua Roca. Barcelona.

\section{ABSTRACT}

Antoni de Martí Franquès and Spontaneous Generation: Conflicts between Science and Religion in the Work of a Naturalist.

Antoni de Martí Franquès was a naturalist from Tarragona, who lived in the second half of the eighteenth century and early nineteenth century. He was best known for his remarkable experiments devoted to investigating the composition of atmospheric air, and he also devoted a good deal of his experimental work to studying spontaneous generation. Martí Franquès' surviving manuscripts and the testimony of his contemporaries tell us he was convinced that he had experimentally proven the existence of this phenomenon. However, being a devout Catholic, he refused to publish anything on this subject during his lifetime for fear of being accused of heresy. What is more, his descendants also refrained from publishing any of his work posthumously due to religious prejudices.

Keywords: Antoni de Martí Franquès, spontaneous generation, eighteenth and nineteenth centuries, Catalonia, religion.

Agustí Camós. CFA El Clot (Barcelona). Membre de la Societat Catalana d'Història de la Ciència i de la Tècnica i del Centre d'Història de la Ciència de la Universitat Autònoma de Barcelona. 